\title{
Fracture Penis - An atypical presentation
}

\author{
Pogula Vedamurthy Reddy ${ }^{1}$, Byram R. ${ }^{2}$, Manne V. ${ }^{3}$, Gouru Vijaya Bhaskar R. ${ }^{4}$, Bodduluri S. ${ }^{5}$, \\ Maddiboina H.K. ${ }^{6}$ \\ ${ }^{1}$ Dr. Vedamurthy Reddy Pogula, ${ }^{2}$ Dr. Ranadheer Byram, ${ }^{3}$ Dr. Venu Manne, ${ }^{4}$ Dr. Vijaya Bhaskar Reddy Gouru, \\ ${ }^{5}$ Dr. Sudeep Bodduluri, ${ }^{6}$ Dr. Hari Krishna Maddiboina, all authors are affiliated with Dept of Urology \& Renal \\ Transplantation, Narayana Medical College \& Hospital, Nellore, Andhra Pradesh, India
}

Address for Correspondence: Dr. Vedamurthy Reddy Pogula, Dept of Urology \& Renal Transplantation, Narayana Medical College \& Hospital, Nellore, Andhra Pradesh, India - 524003, Email: pglreddy@yahoo.co.in

\begin{abstract}
Blunt penile traumatic injury is usually of concern only with an erect penis, when fracture of the tunica albuginea may result. Here we report a case of fracture penis with an atypical presentation.
\end{abstract}

Key words: Fracture penis; Blunt penile trauma; Tunica albuginea tear

\section{Introduction}

Traumatic injuries to the genitalia are uncommon, in part because of the mobility of the penis and scrotum. Penile fractutre is an uncommon presentation to Urology departments with an incidence of 1 in 175,000 [1]. It is defined as the traumatic rupture of the tunica albuginea of the corpora cavernosum; common culprits are intercourse when the penis strikes the perineum or masturbation. Other causes include rolling over in bed on to the erect penis, forced flexion to achieve detumescence and external blunt trauma [2]. A widely held view is that the 'woman on top' position poses the greatest risk to penile fracture although no systematic review has corroborated this. Analysing the literature would seem to suggest a geographical variation in the aetiology of penile fracture [3]. In some middle eastern countries, many reported cases are due to patients 'kneading and snapping' the erect penis to achieve rapid detumescence in unsuitable situations [2,4,5]. In general, prompt surgical reconstruction of most penile injuries usually leads to adequate and acceptable cosmetic and functional results.

\section{Case report}

A 35year old male was presented with mild pain and swelling at the root of the penis of 10 days duration. The pain started suddenly during sexual intercourse and was followed by swelling in the penoscrotal region. His pain decreased in intensity with analgesics but the swelling persisted. Few days later on attempted sexual intercourse he had non-rigid erection and severe pain. On examination, he was afebrile, penile shaft was normal and a 5 x 6 cm swelling was noted at penoscrotal region (Fig. 1).

The swelling was mildly tender and soft cystic in consistency. Scrotal Ultrasound revealed highly echogenic material in the swelling and tunica could not be assessed. With a clinical suspicion of penile fracture MR imaging of penoscrotal region was done. MRI confirmed the clinical diagnosis and revealed a $7 \mathrm{~mm}$ tunical tear in left corpus cavernosum near the root of the penis (Fig. 2A, 2B \& 2C). Surgical exploration revealed a large hematoma overlying a tranverse tear in left corpus cavernosum proximally at the root of the penis (Fig. 3). The hematoma was evacuated and the tear was repaired with interrupted sutures (Fig. 4A \& 4B). Post operatively patient has normal erections.

\footnotetext{
Manuscript received: $6^{\text {th }}$ August 2017

Reviewed: $16^{\text {th }}$ August 2017

Author Corrected: $24^{\text {th }}$ August 2017

Accepted for Publication: $31^{\text {st }}$ August 2017
} 


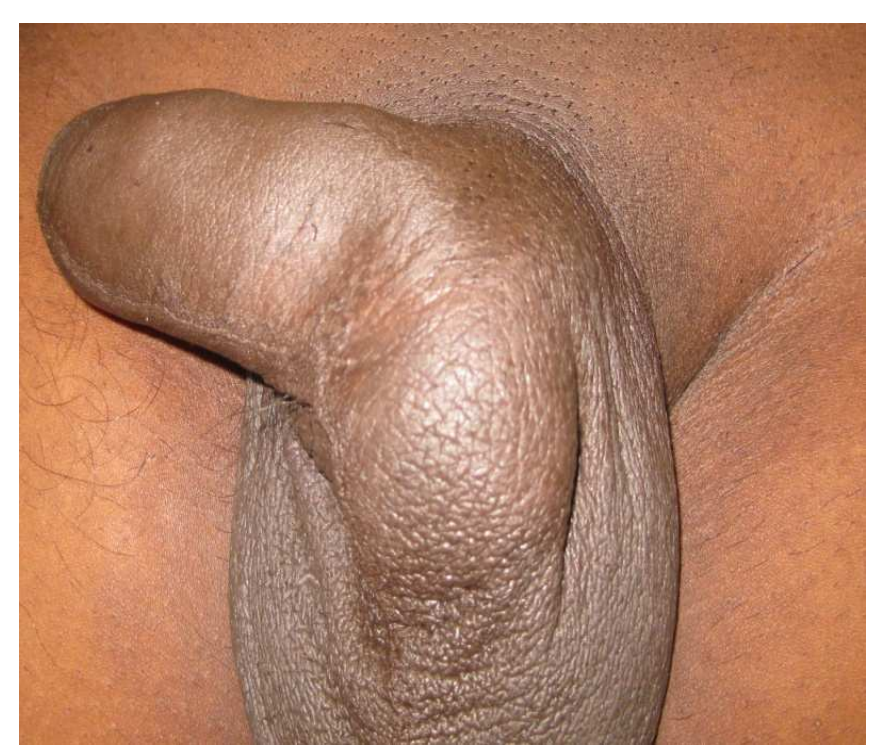

Fig.1

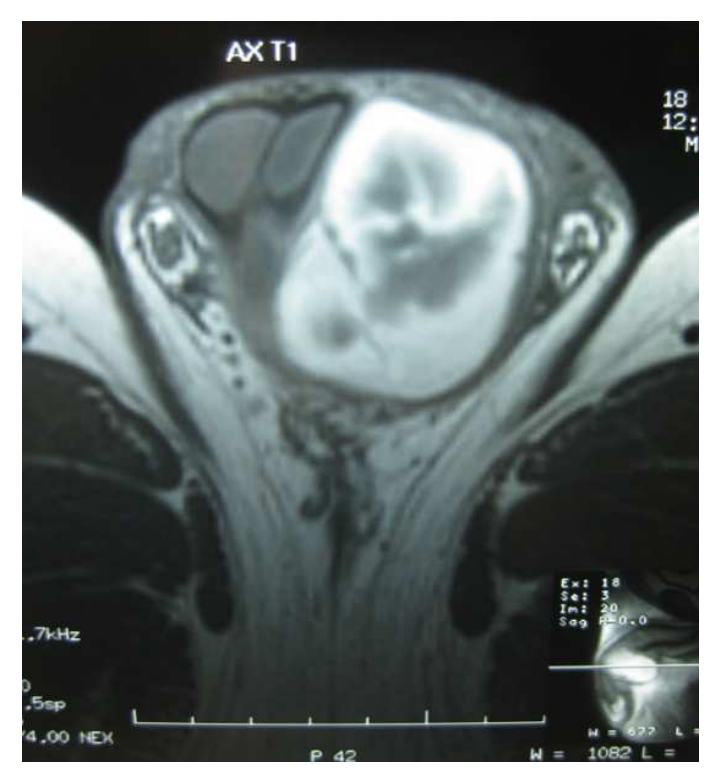

Fig-2B

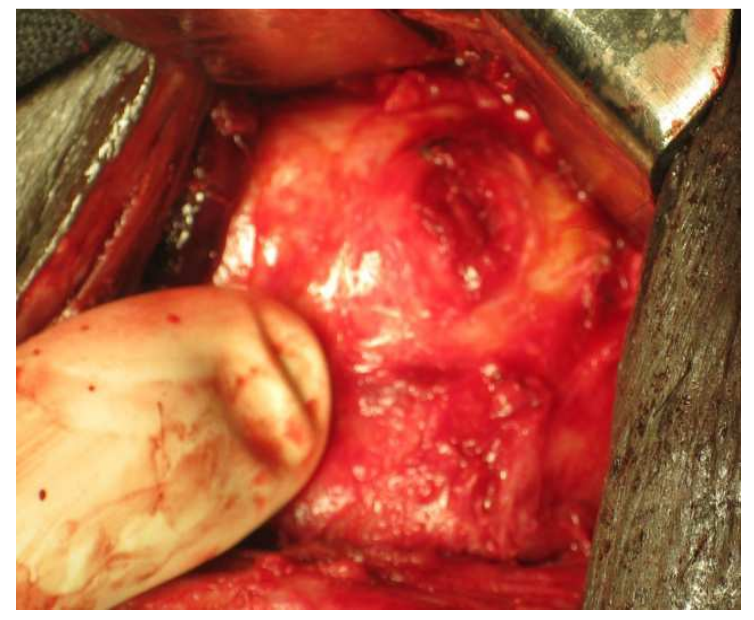

Figure-3

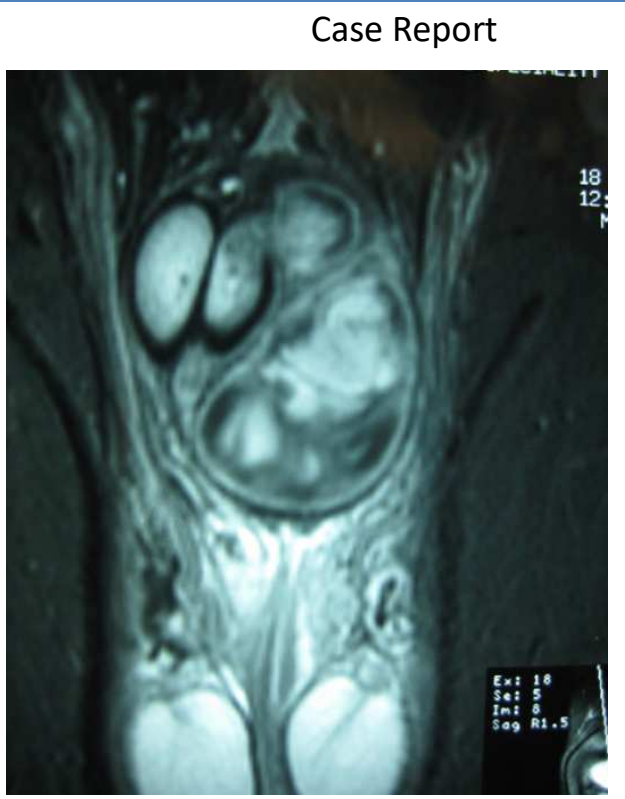

Fig. 2A

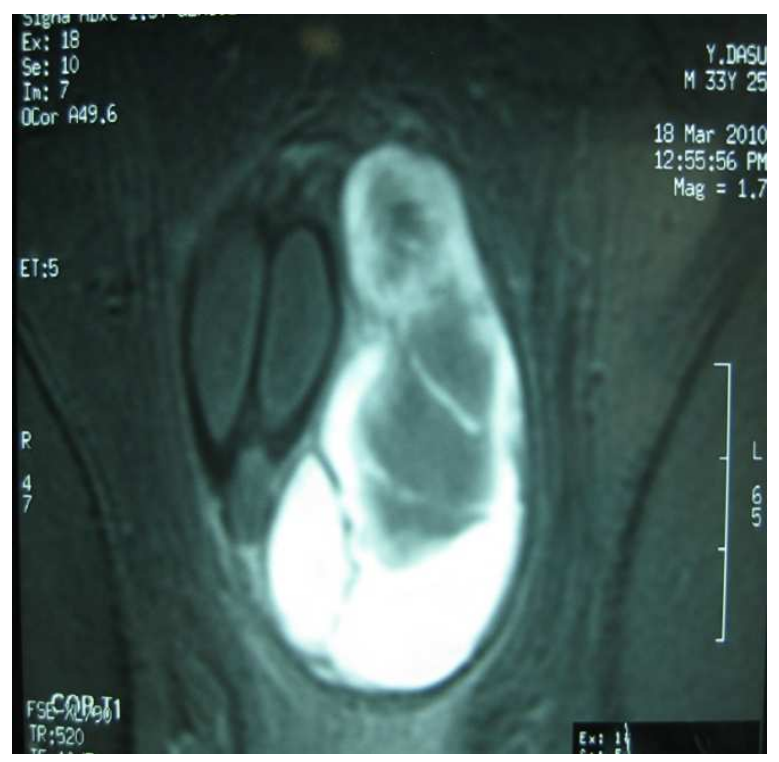

Fig-2C

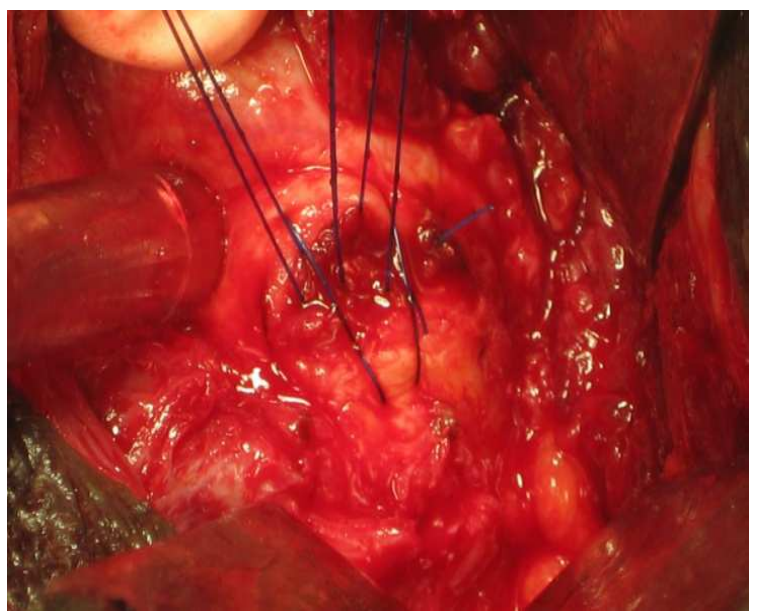

Fig-4A 


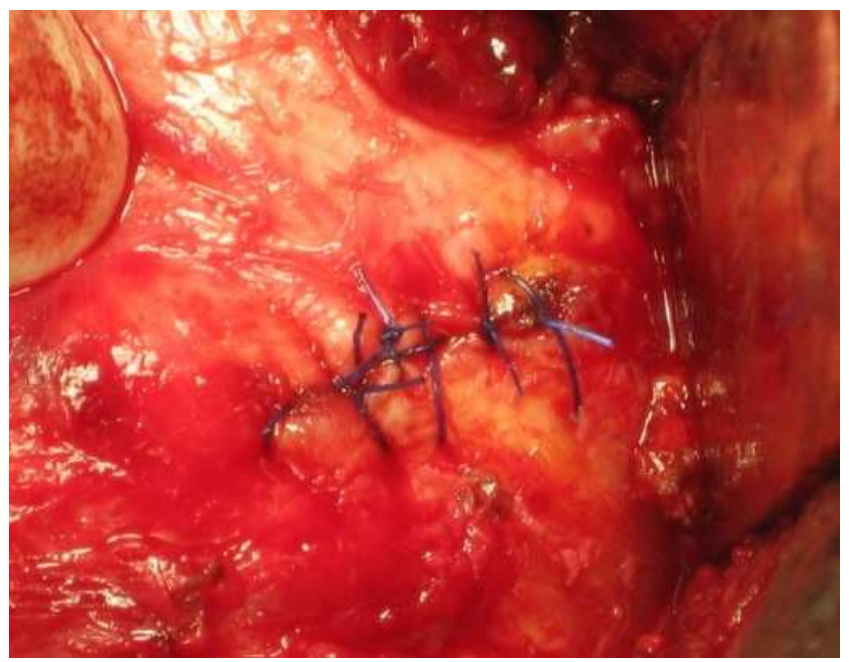

Fig-4B

\section{Figure legends}

Figure 1: Swelling noted at penoscrotal region

Figure 2A, 2B and 2C: MRI revealed a $7 \mathrm{~mm}$ tunical tear in left corpus cavernosum near the root of the penis with hematoma.

Figure 3: Surgical exploration revealed a large hematoma overlying a tranverse tear in left corpus cavernosum proximally at the root of the penis

Figure 4A \& 4B: The hematoma was evacuated and the tear was repaired with interrupted sutures

\section{Discussion}

Penile fracture is the disruption of the tunica albuginea with rupture of the corpus cavernosum. Fracture typically occurs during vigorous sexual intercourse, when the rigid penis slips out of the vagina and strikes the perineum or pubic bone (faux pas du coit), sustaining a buckling injury. The tunica albuginea is a bilaminar structure (inner circular, outer longitudinal) composed of collagen and elastin. The outer layer determines the strength and thickness of the tunica, which varies in different locations along the shaft [6].

The tensile strength of the tunica albuginea is remarkable, resisting rupture until intracavernous pressures rise to more than $1500 \mathrm{~mm} \mathrm{Hg}$ [7]. When the erect penis bends abnormally, the abrupt increase in intracavernosal pressure exceeds the tensile strength of the tunica albuginea, and a transverse laceration of the proximal shaft usually results.

Whereas penile fracture has been reported most commonly with sexual intercourse, it has also been described with masturbation, rolling over or falling on to the erect penis, and myriad other scenarios. In the Middle East, self-inflicted fractures predominate; the erect penis is forcibly bent during masturbation or as a means to achieve rapid detumescence, the practice of taghaandan. The tunical tear is usually transverse and 1 to $2 \mathrm{~cm}$ in length [8]. The injury is usually unilateral, although tears in both corporal bodies have been reported $[8,9]$. Although the site of rupture can occur anywhere along the penile shaft, most are distal to the suspensory ligament.

The diagnosis of penile fracture is often straightforward and can be made reliably by history and physical examination alone. Patients usually describe a cracking or popping sound as the tunica tears, followed by pain, rapid detumescence, and discoloration and swelling of the penile shaft. If Buck's fascia remains intact, the penile hematoma remains contained between the skin and tunica, resulting in a typical eggplant deformity.

If Buck's fascia is disrupted, hematoma can extend to the scrotum, perineum, and suprapubic regions. The swollen, ecchymotic phallus often deviates to the side opposite the tunical tear because of 
hematoma and mass effect. The fracture line in the tunica albuginea may be palpable. A blood clot directly against the fracture site can be palpated; the "rolling sign" describes a firm, mobile, discrete, tender swelling over which the penile skin can be rolled. Because fear and embarrassment are commonly associated, the patient's presentation to the emergency department or clinic is sometimes significantly delayed.

The incidence of urethral injury is significantly higher in the United States and Europe (20\%) than in Asia and the Middle East (3\%), probably owing to the different etiology-intercourse trauma versus self-inflicted injury [4]. Most urethral injuries are associated with gross hematuria, blood at the meatus, or inability to void, although the absence of these findings does not definitively rule out urethral injury [4]. Given that urethral injury occurs not infrequently and that urethrography is a simple and reliable study, clinicians should have a low threshold for urethral evaluation in all cases of penile fracture.

The typical history and clinical presentation of fractured penis usually make adjunctive imaging studies unnecessary. Cavernosography is discouraged in the evaluation of a suspected penile fracture because it is time-consuming and unfamiliar to most urologists and radiologists [10].

Ultrasonography, although noninvasive and easy to perform, has also been associated with significant falsenegative studies [11]. Magnetic resonance imaging is a noninvasive and highly accurate means of demonstrating disruption of the tunica albuginea [11]. Arguments against the routine use of magnetic resonance imaging are the expense, limited availability, and time requirements involved with the study. Magnetic resonance imaging is reasonable in the evaluation of patients without the typical presentation and physical findings of penile fracture.

False fracture has been reported in patients who present with penile swelling and ecchymosis, although they do not describe the classic "snappop" or rapid detumescence typically associated with fracture. Physical examination may not be adequate for definitive diagnosis of a corporal tear in these circumstances [12]. Surgical exploration or evaluation with magnetic resonance imaging should be considered. Another condition that may mimic penile fracture is rupture of the dorsal penile artery or vein during sexual intercourse [13]. Multiple contemporary publications indicate that suspected penile fractures should be promptly explored and surgically repaired. Broad-spectrum antibiotics and 1 month of sexual abstinence are recommended.

Immediate surgical reconstruction results in faster recovery, decreased morbidity lower complication rates, and lower incidence of long-term penile curvature $[9,14]$. Conservative management of penile fracture results in penile curvature in more than $10 \%$ of patients, abscess or debilitating plaques in $25 \%$ to $30 \%$, and significantly longer hospitalization times and recovery [14].

\section{Conclusion}

Penile fracture is a commonly missed and underreported condition. The diagnosis is more often clinical and prompt surgical exploration is the treatment of choice.

\section{Funding: Nil, Conflict of interest: None Permission of IRB: Yes}

\section{References}

1. Kofiman L, Barros R, Junior RA, Cavalcanti AG, Favorito LA: Penile fracture: diagnosis, treatment and outcomes of 150 patients. Urology 2010; 76:1488-1492

2. Ateyah A, Mostafa T, Nasser TA, Shaeer O, Hadi AA, Al-Gabbar MA: Penile fracture: surgical repair and late effects on the erectile function. $J$ Sex Med 2008; 5:1496-1502.

3. Reis LO, Cartapatti M, Marmiroli R, de Oliveria Junior EJ, Saade RD, Fregonesi A: Mechanisms predisposing penile fracture and long-term outcomes on erectile and voiding functions. Adv Urol 2014; 2014:768158.

4. Jack GS, Garraway I, Reznichek R, Rajfer J: Current treatment options for penile fractures. Rev Urol 2004; 6:114-120.

5. Zargooshi J: Sexual function and tunica albuginea wound healing following penile fracture: an 18-year follow-up study of 352 patients from Kermanshah, Iran. J Sex Med 2009; 6:1141-1150. 
6. Brock G, Hsu G, Nunes L, von Heyden B, Lue TF: The anatomy of the tunica albuginea in the normal penis and Peyronie's disease. J Urol 1997; 157:276-281.

7. Bitsch M, Kromann-Andersen B, Schou J, Sjontoft E: The elasticity and tensile strength of tunica albuginea of the corpora cavernosa. J Urol 1990; 143:642-645.

8. Mydlo JH: Surgeon experience with penile fracture. J Urol 2001; 166:526-529.

9. El-Taher AM, Aboul-Ella HA, Sayed MA, Gaafar AA: Management of penile fracture. $J$ Trauma 2004; 56:1138-1140.

10. Morey AF, Metro MJ, Carney KJ, Miller SK, McAninch JW: Consensus on genitourinary trauma. BJU Int 2004; 94:507-515. doi.org/10. 1111/j.1464-410X.2004.04993.x
11. Fedel M, Venz S, Andreessen R, Sudhoff F, Loening SA al: The value of magnetic resonance imaging in the diagnosis of suspected penile fracture with atypical clinical findings. $J$ Urol 1996; 155:1924-1927.

12. Shah DK, Paul EM, Meyersfield SA, Schoor RA: False fracture of the penis. Urology 2003; 61:1259.

13. Nicely ER, Costabile RA, Moul JW: Rupture of the deep dorsal vein of the penis during sexual intercourse. J Urol 1992; 147: 150152.

14. Nicolaisen GS, Melamud A, Williams RD, McAninch JW: Rupture of the corpus cavernosum: Surgical management. J Urol 1983; 130: 917-919.

\section{How to cite this article?}

Pogula Vedamurthy Reddy, Byram R, Manne V, Gouru Vijaya Bhaskar R, Bodduluri S, Maddiboina H.K. Fracture Penis- An atypical presentation. Int J Med Res Rev 2017;5(08):791-795.doi:10.17511/ijmrr. 2017.i08.03. 